\title{
Self-directed E-Learning in Under Graduate Medical Teaching
}

\author{
Author \\ Preethi M. Shenoy \\ Associate Professor, Department of Biochemistry, JMMC \& RI, Thrissur, Kerala, India \\ Corresponding Author \\ Preethi M. Shenoy \\ Email:pmsn@live.in
}

\begin{abstract}
Introduction: E-learning or internet based learning, in various forms, is being implemented as a teachinglearning method and is hypothesized to replace traditional learning methods. In this context, there are questions raised regarding its effectiveness in medical education. The study sought to assess the effectiveness of self-directed e-learning against traditional lecture among first year medical students.

Materials and Methods: A quasi-experimental study in which three groups of first year medical students were provided with either didactic lecture, self-directed e-learning or both was followed by a post-test in an objective format.

Result: Based on the score of the post-test, the students who attended an exclusive traditional didactic lecture, performed better than those students who followed the self-directed e-learning method. The result of the study is in contrast to previous studies which support e-learning. The reasons could be due to the difference in target population, post-test tool and the domain assessed.

Conclusions: We can hence conclude that e-learning as a method of learning cannot be implemented as a stand-alone method, across the student population, rather it can be used as a blended learning tool.

Keywords- Effectiveness, self-directed e-learning, traditional didactic lecture.
\end{abstract}

\section{Introduction}

Learning, by definition is the acquisition of knowledge or skills through study, experience, or being taught ${ }^{[1]}$. The newer technique of E-learning is learning conducted via electronic media, typically on the Internet ${ }^{[2]}$. There is an increasing dependence on e- learning world over, in recent years. E-learning is said to allow learners to tailor their educational experiences to meet their personal learning objectives with more control over the learning process ${ }^{[3]}$. Medical universities are including e-learning modality in the curriculum. The E-learning technologies cater to learners with different learning styles and strengths in multiple domains of learning. The medical students and residents as adult learners can choose when, where and how they learn using the e-learning platform ${ }^{[3]}$. E-learning as a part of tele-education has gained popularity but its use is variable among medical schools and is implemented more commonly in basic medical science courses than in clinical education. Here the e- learning does not exclude traditional learning processes; it is used in conjunction with in-person classroom or professional training in procedures and practical skills. Tele-education has been used in biomedical 
education as a blended learning method, combining technology with traditional instructor-led training, for example, when a lecture or demonstration is supplemented by an online tutorial ${ }^{[4]}$.

Many ways in which e-learning is put to use in medical curriculum include using specificallydesigned courses, or using virtual classes as in anatomy dissection ${ }^{[5]}$. E-learning also broadly includes self- directed learning using internet resources. A study from Poland showed that the elearner performed better than the traditional learner and also was more motivated to achieve learning goals ${ }^{[6]}$. Another study showed that both e-learning program and written textual material yielded significant improvement in conceptual knowledge and self-perceived competency, without any significant difference between both interventions ${ }^{[7]}$. Another research concluded that situated e-learning had limited improvement of cognitive ability when compared to traditional learning. Situated e-learning is a useful adjunct to traditional learning for medical and nursing students ${ }^{[8]}$. The field of Medicine is unique because the expectation from learners requires them to achieve a high level of precise knowledge and practical skills in the subject pursued. Hence there is a question of the effectiveness of e-learning as a stand-alone method to attain the required expertise. Moreover, the novice students of the first year of undergraduate MBBS course may not have previous exposure to the use of the e-learning platform on an extensive level. The author therefore, decided to conduct this study to compare the effectiveness of e-learning with the traditional learning technique - the didactic lecture. In the study, three groups of students were selected, each group was provided with didactic lecture or self-directed e-learning or both learning techniques, respectively, and their level of performance was assessed using an objective evaluation test. The role and the effectiveness of self-directed e-learning as a stand-alone method of learning were compared with traditional didactic lecture using a post-test. The level of post-test performance of groups of students who underwent e-learning, didactic lecture or both was analyzed.

\section{Materials and Methods}

The study design is quasi-experimental with three groups of students. The groups included twenty $(n=20)$ students each of first MBBS course adding to a total of 60 students. The students were selected by random allocation. The grouping was done as follows:

Group 1 - Self- directed e-learning using internet resources

Group 2 - Traditional didactic lecture

Group 3 - Traditional didactic lecture followed by self- directed e-learning.

The study was conducted in a time span of three hours on a regular working day. The topic was selected from the syllabus of Biochemistry for the first MBBS such that it will be covered within the specified time- frame. The Specific Learning Objective (SLO) for the module was intimated to the three groups of students at the beginning of the study. A didactic classroom lecture was given to two groups during the first hour (Groups 2 and 3). Meanwhile, group $1 \mathrm{did}$ an exclusive self-directed learning using internet resource on the same topic in another classroom. During the second hour, group 2 students who received the didactic lecture revised the topic, based on the notes taken-down during the lecture class. Group 3, which obtained didactic lecture conducted self-directed learning on the topic using internet resources during the second hour. The e- learning group 1 continued with the self-directed study for the prescribed two hours. Based on the SLO, all three groups of students were simultaneously evaluated using a post-test that consisted of multiple choice questions and true or false type of 30 items. The test was conducted during the third hour. The scores obtained in the post-test by the students were compared.

Statistical methods - The statistical analysis was done using IBM SPSS 20 version. All continuous parameters are presented as mean $+/-$ standard deviation. Multiple comparisons was done using Bonferroni test. 


\section{Results}

The scores obtained were analyzed by calculating the mean and standard deviation. The mean of points scored by group 1 was $50 \%$; group 2 is $73 \%$, and group 3 is $70 \%$ of the total score. The standard deviation was the least for group 2 (lecture group). The maximum score was highest for the group 3 (lecture + e-learn) and the minimum was lowest for group 1(e-learn).

Using ANOVA the mean scores of the three groups was compared. There was significant difference (0.000) between the scores of the group 1 (elearning) and group 2 (lecture) *. The difference in the scores of groups 1 (e-learning) and 3 (lecture and e-learning) is also significant statistically (0.000). There is no significant difference in mean scores of groups 2 (lecture) and 3(lecture + e-learn). (*The mean difference is significant at the $\mathrm{p}$ value of 0.05 or less.)

\section{Discussion}

The present study shows that the e-learners had a mean score of $50 \%$, whereas, the traditional learners and the traditional followed by e-learning combination group had much higher mean scores. The lowest score was for one student in the elearning group and the highest score was for a student of the group that received lecture followed by e-learning. Moreover, the standard deviation is least for the lecture group $(\mathrm{SD}=1.7)$. The findings suggest that the subjects of the traditional lecture group performed almost equally in the post-test and hence had effective knowledge- gain based on the SLO. But the e-learners were unable to acquire the knowledge level as per the SLO.

This finding is in contrast to the study where a webbased learning group and a control group that received identical educational content demonstrated no difference in knowledge gains between groups ${ }^{[9]}$. Whereas, another study conducted to assess the effectiveness of web-based continuing medical education demonstrated a significant knowledge gain ${ }^{[10]}$. The subjects of the study were practicing physicians who were adult learners. Adult learners have intrinsic motivation to improve knowledge and expertise in the area of their interest. In another study conducted to evaluate a stand-alone webbased computer-aided learning program for dentists, the comparison was done not with traditional lecture, rather with text book and audio-visual aids ${ }^{[11]}$.

The difference in performance of the subjects in the present study may be attributed to the reason that the subjects were novice to the use of internet for educational purpose as first year medical students. They may not be familiar with the relevant websites. The allotted time for the self-directed elearning may have been a deterrent in the post-test performance. They were restricted by the timeframe of two hours set for attaining the goal. The traditional lecture effectiveness does depend on the initiative of the teacher which reflects on the good performance of the lecture group. Evaluation methods also have to be multi-pronged to assess the learner. In the present study, only one type of assessment tool was used. Moreover, the cognitive domain alone was evaluated and the affective and psychomotor domains of Bloom's taxonomy of learning domains were not. The results of the present study suggest that interactive lecture classes are an effective modality of learning, especially for the novice.

Table 1 - Mean scores obtained by the students in the three groups, and the standard deviation

\begin{tabular}{|l|c|c|c|}
\hline & $\begin{array}{c}\text { E-Learn } \\
\text { Group 1 }\end{array}$ & $\begin{array}{c}\text { Lecture } \\
\text { Group 2 }\end{array}$ & $\begin{array}{c}\text { Lecture + E-Learn } \\
\text { Group 3 }\end{array}$ \\
\hline $\mathrm{N}$ & 20 & 20 & 20 \\
\hline Mean & 15.70 & 22.05 & 20.70 \\
\hline Std. Deviation & 3.701 & 1.701 & 3.373 \\
\hline Minimum & 8 & 20 & 14 \\
\hline Maximum & 21 & 26 & 27 \\
\hline
\end{tabular}


Table 2 - Comparison of the 3 groups for difference in marks obtained in post-test

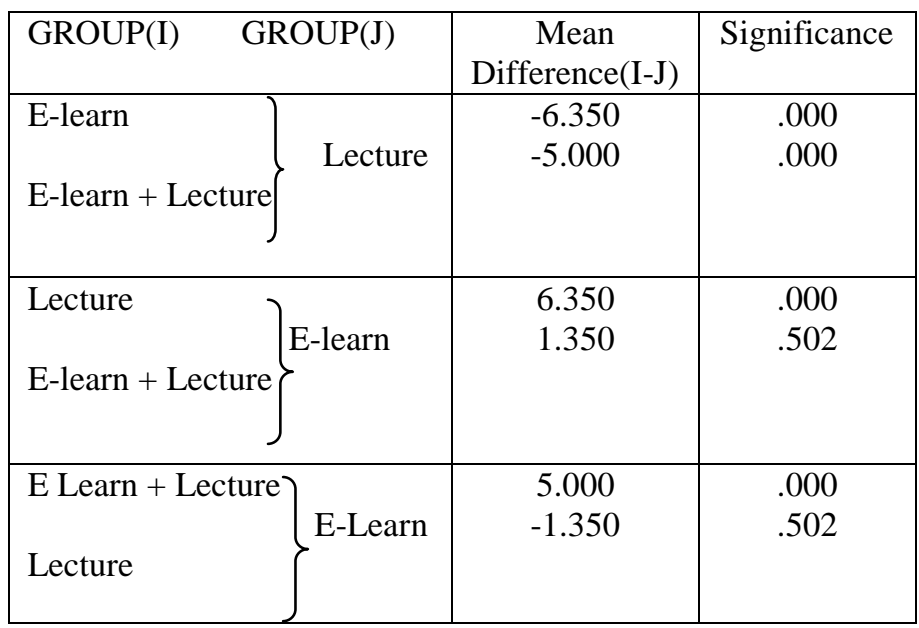

(The mean difference is significant at the $\mathrm{p}$ value of 0.05 or less.)

\section{Conclusions}

From the findings of the study we can conclude that the level of performance of self- directed e-learner is less than the receiver of the traditional lecture in terms of knowledge gains. Whereas, the level of performance of those receiving traditional lecture who later practiced self-directed e-learning is equal to that of the traditional lecture group in terms of knowledge gains. An unstructured self- directed elearning module as a stand-alone method to achieve knowledge is not as effective as a traditional lecture for first year medical undergraduates in the subject of Biochemistry.

\section{Recommendations and Suggestions}

The field of undergraduate medical education encompasses learning goals which will assess the three domains- the cognitive, psychomotor and affective, spanning the entire course. It has been shown that the e-learning modules were preferred by majority of medical students and thus is an effective tool to deliver conceptual knowledge. As per the researchers, quantitative aspect alone does not allow for an accurate evaluation of the impact of the e-learning program on medical students. In fact, the qualitative data are fundamental for an authentic appraisal of the e-learning as a learning method and a thorough inquiry about the students' conceptual knowledge acquisition following the use of the e- learning program ${ }^{[3]}$. Further, e-learning may have different effectiveness in the subjects in the different semesters of the undergraduate medical course. Hence the e-learning modules must be specifically designed to enhance the gains obtained by traditional didactic lecture by including recent advances and case-studies followed by the multipronged evaluation of the learner. It is not effective when the learner has to choose the relevant information, especially in the early years in medical school. The effectiveness of e- learning has to be compared with subjects from the advanced years of undergraduate medical course to obtain a clearer picture.

\section{Acknowledgements}

This research was a conducted as part of Basic course in Medical Education Technology organized by RCMET, MC, Kozhikode, Kerala, India. The author thanks Dr. P. Krishna Kumar, Department of Pediatrics, GMC, Kozhikode for valuable suggestions and review of the work. My thanks and appreciation is also due to colleagues from PKDIMS, Kerala, India for the help received for the research.

\section{References}

1. Definition of learning in English: Available at: https://en.oxforddictionaries.com/definition/learning

2. Definition of e-learning in English: Available at: https://en.oxforddictionaries.com/definition/e-learning

3. University of Toronto, Faculty of Medicine, Office of Integrated Medical Education. ELearning Resources at the Faculty of Medicine. Available at: http://oime.utoronto.ca/Faculty/E-Learning_Resources.htm (accessed 11/01/2017).

4. Masic I. E-Learning as New Method of Medical Education. Acta Inform Med. 2008;16 (2):102-17.

5. Moazami F, Bahrampour E, Azar MR, Jahedi $F$ and Moattari M. Comparing two methods of education (virtual versus 
traditional) on learning of Iranian dental students: a post-test only design study. BMC Medical Education. 2014;14( 45)

6. Święczkowska H, Trzęsicki K, Surowik D, Doliwa K, editors. Logic, philosophy and computer science - series: studies in logic, grammar and rhetoric. 1st ed. Poland; 2010. p (159-165)

7. Gruner D, Pottie K, Archibald D, Allison J, Sabourin V, Belcaid I, McCarthy A, Brindamour M, Polec LA, Duke P. Introducing global health into the undergraduate medical school curriculum using an e-learning program: a mixed method pilot study. BMC Medical Education. 2015; 15( 142)

8. Feng J-Y, ChangY-T, Chang H-Y, Erdley WS, Lin C-H, Chang Y-J. Systematic Review of Effectiveness of Situated ELearning on Medical and Nursing Education. Worldviews on Evidence-Based Nursing. 2013;10(3):174-183

9. Woo MA, Kimmick JV. Comparison of internet versus lecture instructional methods for teaching nursing research. J Prof Nurs.. 2000;16(3):132-9.

10. Curran VR, Hoekman T, Gulliver W, Landells I, Hatcher L. Web-based continuing medical education. (II): Evaluation study of computer-mediated continuing medical education. J Contin Educ Health Prof. 2000;Spring;20(2):106-19

11. Perryer G, Walmsley AD, Barclay CW, Shaw L, Smith AJ. Development and evaluation of a stand-alone web-based CAL program. A case study. Eur J Dent Educ. $2000 ; 4(3): 118-123$. 